\title{
Anne Richardot, Le rire des Lumières
}

\section{Alessandra Rollo}

\section{(2) OpenEdition}

\section{Journals}

\section{Edizione digitale}

URL: https://journals.openedition.org/studifrancesi/40692

DOI: 10.4000/studifrancesi.40692

ISSN: 2421-5856

\section{Editore}

Rosenberg \& Sellier

\section{Edizione cartacea}

Data di pubblicazione: 1 juillet 2004

Paginazione: 191

ISSN: 0039-2944

\section{Notizia bibliografica digitale}

Alessandra Rollo, «Anne Richardot, Le rire des Lumières», Studi Francesi [Online], 142 (XLVIII | I) | 2004,

online dal 30 novembre 2015, consultato il 09 septembre 2021. URL: http://journals.openedition.org/ studifrancesi/40692 ; DOI: https://doi.org/10.4000/studifrancesi.40692

\section{Questo documento è stato generato automaticamente il 9 septembre 2021.}

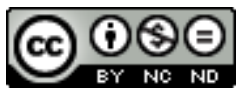

Studi Francesi è distribuita con Licenza Creative Commons Attribuzione - Non commerciale - Non opere derivate 4.0 Internazionale. 


\title{
Anne Richardot, Le rire des Lumières
}

\author{
Alessandra Rollo
}

\section{NOTIZIA}

ANNE RICHARDOT, Le rire des Lumières, Paris, Honoré Champion, 2002, («Les dix-huitièmes siècles») pp. 317.

1 Nel presente volume, che si articola in quattro parti precedute da un'introduzione, Anne Richardot si propone di evidenziare il rapporto di complicità e di conflittualità tra il «rire» e la sensibilità del XVIII secolo che si colloca sotto l'egida della giocosità, dell'effervescenza, della verve satirica e delle celebrazioni festose della Rivoluzione.

Nella prima sezione, intitolata "Convulsion et compassion», è presentato il nuovo ideale di uomo che si delinea nel ' 700 , caratterizzato dalla riconciliazione tra esigenze fisiche, spirituali ed intellettuali. In un rifiorire d'interesse ermeneutico per il riso, emozione la cui natura risulta di difficile definizione, i commentatori ne riconoscono le virtù sociali, quasi catartiche, ma si sforzano di arginarne le manifestazioni convulse $\mathrm{e}$ l'erotismo latente, per ragioni di ordine scientifico e morale. In nome di un nuovo imperativo umanistico, il secolo dei Lumi rivendica, nella letteratura e nella vita, un atteggiamento di empatia e di «compassion» che mal si accorda col riso, associato alla beffa e alla follia. Da qui deriva la generale condanna del «rieur», stigmatizzato per la sua scarsa socializzazione e solidarietà. Il profilo dei «philosophes» tracciato dall'Encyclopédie è quello di uomini sensibili che, prendendo le distanze da Democrito filosofo la cui proverbiale ilarità era un tempo ritenuta segno di superiorità intellettuale - sono più affini ad Eraclito, perfetta incarnazione della sensibilità preconizzata dall'llluminismo.

3 Nella seconda parte, dal titolo «De la raillerie au persiflage», l'autrice ripercorre l'evoluzione del «rire» che nel XVII secolo anima la vita mondana, divenendo il condimento di ogni discussione. "Art de vivre élitiste», il motteggio è indice di elezione intellettuale, appannaggio dell'«honnête homme», il solo che sia capace di far ridere e divertire senza scadere nella volgarità. Lo scherzo e la facezia fungono altresì da 
lubrificante sociale e da elemento di coesione all'interno di un gruppo. Se nel '600 savoir-rire equivale a savoir-vivre, nel secolo successivo i commentatori criticano la degenerazione del «rire» in ironia maliziosa e, talvolta, in vera e propria aggressione. I salotti pullulano di «petits-maitres» che intraprendono la via della frivolezza insolente, del narcisismo sarcastico e sprezzante, fino alla maldicenza. La «raillerie» assume così una connotazione peggiorativa, sfociando in "persiflage», mezzo di espressione privilegiato secondo il nuovo codice mondano; «l'homme sociable» cede il passo a quello che Duclos chiama «l'homme aimable», definito dall'Encyclopédie come colui che non ama nessuno e non è amato da nessuno, ma riesce comunque a sedurre tutti.

Nella terza sezione, intitolata «Rire national, Rire politique», Anne Richardot sottolinea la superiorità della Francia, nel XVIII secolo, sulle altre nazioni europee, per la sua naturale propensione al «rire» e alla satira raffinata. Dinanzi al proliferare di feste religiose e politiche, aventi lo scopo di offrire un diversivo al popolo, Rousseau osserva come il "divertissement» sia uno strumento di manipolazione politica; lungi dal rappresentare un momento di aggregazione della collettività, saturnali e pastorali hanno a suo avviso soffocato la gioia semplice che contraddistingue le feste popolari e campestri. All'indomani del 1789 si assiste a quello che i promotori della Rivoluzione giudicano un autentico risveglio del «rire» patriottico e dell'euforia rivoluzionaria pura e spontanea, che trovano il principale veicolo nei libelli politici e segnano il trionfo del popolo sull'aristocrazia e sulla famiglia reale.

Nella quarta ed ultima sezione, dal titolo «La littérature au péril du rire», viene illustrato il ruolo del «rire» nell'opera di Rousseau e Diderot. Il primo rivela in vari scritti autobiografici un'autentica vena umoristica ed un'ironia benevola nei confronti delle proprie chimere e delle stravaganze del passato. C'è, in realtà, una profonda ambivalenza nella dinamica psicologica rousseauiana: prestando il fianco al ridicolo e al giudizio beffardo del pubblico, lo scrittore vuole esorcizzare il vilipendio dei lettori, recuperando lo spessore umano perduto. Anche la posizione di Diderot è bipolare, con un'alternanza di diffidenza e d'interesse verso il riso. Il processo estetico tracciato nella sua opera finisce col riflettere i valori dominanti del regime politico: come Rousseau, Diderot assimila il riso, e con esso l'elemento comico/grottesco, alla tradizione aristocratica, laddove il tragico è proprio della spirito repubblicano. Un lucido esame della produzione diderotiana - emblematico, a tal riguardo, Le Neveu de Rameau - sfocia costantemente in una dualità irrisolta tra il fascino per l'atteggiamento satirico ed anticonformista e la compostezza morale ed intellettuale.

6 Chiudono il volume una breve conclusione, un'iconografia satirica ed una ricca bibliografia, seguita dall'indice degli autori citati. 